\title{
Increased Number and Expertise of Italian Respiratory High-Dependency Care Units: The Second National Survey
}

\author{
Raffaele Scala MD, Antonio Corrado MD, Marco Confalonieri MD, Santino Marchese MD, and \\ Nicolino Ambrosino MD, on behalf of the Scientific Group on Respiratory Intensive Care of the \\ Italian Association of Hospital Pneumologists
}

\begin{abstract}
BACKGROUND: The imbalance between the increasing prevalence of acutely decompensated respiratory diseases and the shortage of intensive care unit beds has stimulated the growth of respiratory high-dependence care units (RHDCUs). METHODS: We conducted a national survey to analyze the changes, in the past 10 years, in the number, structures, staff, procedures, diagnoses, and outcomes in Italian RHDCUs that satisfy the European Respiratory Society's criteria (modified according to the Italian Association of Hospital Pneumologists) for high level (respiratory intensive care unit), intermediate level (respiratory intermediate intensive care unit), and low level (respiratory monitoring unit) RHDCU care. RESULTS: The number of RHDCUs increased from 26 to 44. The relative prevalence among all the RHDCUs increased only for the low-level units $(P=.03)$. Compared to 1997, in 2007 a higher percentage of Italian RHDCUs were located within respiratory wards than located outside of respiratory wards $(P=.03)$, and the physician-to-patient mean ratio and the nurse-to-patient mean ratio per shift were lower $(P=.001$ and $P=.002$, respectively). Admissions for only monitoring decreased $(P<.001)$, and admissions for active interventions increased: noninvasive ventilation $(P=.002)$, invasive ventilation $(P<.001)$, weaning from invasive ventilation $(P<.001)$, and tracheal decannulation $(P<.001)$. The complexity of RHDCU patients' conditions increased: there was a reduction in the percentage of COPD patients $(P<.001)$ and an increase in the percentage of patients with neuromyopathies $(P<.001)$ and de novo hypoxemia $(P=.006)$. CONCLUSIONS: Between 1997 and 2007 there was an increase in the number and expertise of Italian RHDCUs, with a shift toward less expensive care, and greater complexity of interventions and patient dysfunctions. These findings support the crucial role of RHDCUs in the management of respiratory critical patients. Key words: acute respiratory failure; mechanical ventilation; noninvasive mechanical ventilation; respiratory high-dependence care unit; survey; tracheostomy; weaning. [Respir Care 2011;56(8):1100-1107. (C) 2011 Daedalus Enterprises]
\end{abstract}

\footnotetext{
Dr Scala is affiliated with Unità Operativa di Pneumologia, Unità di Terapia Semi-Intensiva Respiratoria e Interventistica, Ospedale Campo di Marte, Lucca, Italy. Dr Corrado is affiliated with Unità di Terapia Intensiva Respiratoria, Azienda Ospedaliero, Universitaria Careggi, Firenze, Italy. Dr Confalonieri is affiliated with Unità Operativa di Pneumologia e Unità di Terapia Intensiva Respiratoria, Ospedale Cattinara, Trieste, Italy. Dr Marchese is affiliated with Unità di Terapia Intensiva Respiratoria, Ospedale Civico L'Azienda di Rilievo Nazionale di Alta Specializzazione, Palermo, Italy. Dr Ambrosino is affiliated with Unità Operativa di Pneumologia, Dipartimento Cardio-Toracico, Azienda Ospedaliero, Universitaria Pisana, Pisa, e Centro di Riabilitazione e Svezzamento Respiratorio, Auxilium Vitae, Volterra, Italy.
}

Dr Scala presented a version of this paper at the 18th Annual Congress of the European Respiratory Society, held October 3-7, 2008, in Berlin,
Germany.

Supplementary material related to this paper is available at http:// www.rcjournal.com.

The authors have disclosed no conflicts of interest.

Correspondence: Raffaele Scala MD, Unità Operativa di Pneumologia, e Unità di Terapia Semi-Intensiva Respiratoria e Interventistica, Ospedale Campo di Marte, Lucca, Italy. E-mail: raffaele_scala@hotmail.com.

DOI: $10.4187 /$ respcare. 01157 


\section{Introduction}

The imbalance between the increasing prevalence of patients with acutely decompensated respiratory diseases ${ }^{1}$ and the shortage of intensive care unit (ICU) beds has stimulated new health solutions. Respiratory high-dependence care units (RHDCUs) provide a specialized quality of care for patients recovering from acute respiratory failure (ARF), with health resources optimization (eg, lower nurse-to-patient ratio). ${ }^{2-6}$ The RHDCU is an intermediatelevel respiratory care setting designed to manage singleorgan decompensations and to avoid the risk of inadequate intensity of care in a lower-level care environment (eg, ward) and the potentially wasteful provision of unnecessarily intensive care in an ICU. Moreover, the RHDCU may act as a step-down unit for post-ICU patients (for weaning and decannulation). ${ }^{2-6}$

\section{See the Related Editorial on Page 1215}

In North America, several levels of RHDCU have been running since the 1960s. ${ }^{7,8}$ In Europe, RHDCUs were set up only in the late 1980s. ${ }^{5}$ However, in Europe there has been a rapid increase in the number of RHDCUs, and the types of RHDCUs differ among the European countries and within given countries, as shown in a European Respiratory Society survey. ${ }^{9}$ This paralleled the expanding popularity of noninvasive ventilation (NIV) to treat ARF. ${ }^{10-12}$ The 68 European surveyed units were classified into 3 levels of care, depending on the resources, the severity of the $\mathrm{ARF}$, and the complexity of the available interventions: respiratory monitoring units (RMUs), respi- ratory intermediate intensive care units (RIICUs), and respiratory intensive care units (RICUs). ${ }^{9}$

In agreement with these European data, in Italy there has been increasing interest in intensive care medicine. ${ }^{13-16}$ Thirty-five percent of the RHDCUs included in the European Respiratory Society survey were in Italy. The only available systematic data on the number, features, and activities of Italian RHDCUs is from a survey performed in 1997. ${ }^{15,16}$ Here we report the second Italian survey of RHDCUs and analyze the changes, from 1997 to 2007, in number, beds, models, staff, equipment, available interventions, and diagnoses and outcomes of the patients.

\section{Methods}

The survey was conducted on behalf of the Scientific Group on Respiratory Intensive Care of the Italian Association of Hospital Pneumologists, in January through March, 2008. The protocol for data analysis was formally reviewed and approved by the ethics committees of all the RHDCUs recruited in the survey.

\section{Definition of Respiratory High-Dependency Care Unit}

To be included in the national survey, the RHDCU had to fully satisfy one of the definitions for RICU, RIICU, or RMU (all major criteria and at least one minor criteria), which were established by the European Respiratory Society ${ }^{9}$ and modified by a recent Italian Association of Hospital Pulmonologists statement ${ }^{14}$ on the definition of RMU: the nurse-to-patient ratio was redefined as between 1:5 and

Table 1. Definitions of the 3 Types of Respiratory High-Dependency Care Unit ${ }^{14}$

\begin{tabular}{|c|c|c|c|}
\hline & $\begin{array}{l}\text { Respiratory Intensive } \\
\text { Care Unit* }\end{array}$ & $\begin{array}{l}\text { Respiratory Intermediate } \\
\text { Intensive Care Unit* }\end{array}$ & $\begin{array}{l}\text { Respiratory Monitoring } \\
\text { Unit* }\end{array}$ \\
\hline \multicolumn{4}{|l|}{ Major Criteria } \\
\hline Nurse:patient ratio per shift & $>1: 3$ & $1: 3$ or $1: 4$ & $1: 5$ or $1: 6$ \\
\hline \multirow[t]{2}{*}{ Bed equipment } & Multi-variable monitors $\dagger$ & Multi-variable monitors $\dagger$ & Multi-variable monitors $\dagger$ \\
\hline & Life-support ventilators & $\begin{array}{l}\text { NIV ventilators and life-support } \\
\text { ventilators }\end{array}$ & NIV ventilators \\
\hline Treatment & $\begin{array}{l}\text { Respiratory failure and } \\
>1 \text { organ failure }\end{array}$ & Respiratory failure and 1 organ failure & $\begin{array}{l}\text { Respiratory failure and } \\
1 \text { organ failure }\end{array}$ \\
\hline Attending physician & $24 \mathrm{~h}$ & Immediately available $24 \mathrm{~h}$ & On call (within the hospital) \\
\hline Mechanical ventilation & Invasive ventilation and NIV & Invasive ventilation and NIV & NIV \\
\hline \multicolumn{4}{|l|}{ Minor Criteria } \\
\hline Bronchoscopy & Inside unit & Inside unit & Inside or outside unit \\
\hline Arterial blood gas analysis & Inside unit & Inside unit & Inside or outside unit \\
\hline \multicolumn{4}{|c|}{$\begin{array}{l}\text { * All major criteria and at least one of the minor must be satisfied to define a unit at each level. } \\
\dagger \text { Oximetry, electrocardiogram, noninvasive blood pressure, respiratory rate. } \\
\text { NIV = noninvasive ventilation }\end{array}$} \\
\hline
\end{tabular}


1:6, which clearly distinguishes the definition of RMU from that of ordinary ward (Table 1). ${ }^{14}$

\section{Selection of the Respiratory High-Dependency Care Units}

Our identification of RHDCUs followed the same procedure applied in the first Italian survey. ${ }^{15,16}$ The RHDCUs were collected on a regional basis under the coordination of a pulmonologist who had been chosen by the Scientific Group on Respiratory Intensive Care of the Italian Association of Hospital Pneumologists during the first survey for his/her interest in intensive care medicine and a thorough knowledge of all the RHDCUs active in his/her geographical area.

Ninety-one RHDCUs were identified: 26 of them had been included in the 1997 survey; the other 65 were known to be potentially working as RHDCUs. The survey included 15 items, on the units' structural features and the characteristics of their populations in 2007 (supplementary material related to this paper is available at http://www. rcjournal.com).

Two months after the first e-mail invitation to participate in the survey, we contacted (via e-mail or telephone) the pulmonologists for the various regions, to resolve any ambiguities. If no reply was received, we used a telephonic and/or e-mail reminder to attempt to obtain the data. Once the surveys were returned, the regional pulmonologist assessed the completeness, accuracy and reliability of the data collected from each RHDCU.

\section{Statistical Analysis}

We compared the 2007 RHDCU survey data to the 1997 data. ${ }^{15,16}$ We used the Kolmogorov-Smirnov test to determine if the data were normally distributed. Continuous data are expressed as mean \pm SD if distributed normally or as median and interquartile range if not. Categorical data are presented as frequencies. We compared continuous variables with the 2-tailed unpaired Student $t$ test (parametric data) or the Mann-Whitney U test (non-parametric data). We compared categorical data with the chi-square test or the Fisher exact test, as appropriate. A $P$ value $<.05$ was considered statistically significant. Analyses were performed with statistics software (SPSS 10.0 SPSS, Chicago, Illinois).

\section{Results}

\section{Number and Geographic Locations}

Eighty-two (90\%) of the 91 RHDCUs responded to the survey. Thirty-eight (46\%) of the 82 respondent units did not fulfill any of the RHDCU definitions: 35 units lacked one major criteria (34 units had a nurse-to-patient ratio
$<1: 6$, and 5 lacked multi-variable monitoring); 3 units lacked both minor criteria. Thirty-four of the 38 excluded units were able to provide NIV. Four of the 26 units that had been surveyed in 1997 were excluded in 2007 because of nursing staff reduction to below the threshold ( 3 units) or closure (one unit). The remaining 44 RHDCUs (see the supplementary materials at http://www.rcjournal.com), which had 228 beds (median 5.0 beds, IQR $4.0-6.0$ beds, per unit), were included in the 2007 survey, compared to the 26 RHDCUs included in the 1997 survey, which had 163 beds (median 5.5 beds, IQR $4.0-8.0$ beds per unit). ${ }^{15}$

In agreement with the 1997 data, the units evaluated in 2007 show a prevalent geographic distribution in the north of Italy $(61 \%)$ versus the center $(21 \%)$ and the south and the islands $(18 \%)$.

Similar to 1997, most (80\%) of the RHDCUs surveyed in 2007 belong to non-university-affiliated hospitals, $18 \%$ belong to private rehabilitation centers, and $2 \%$ belong to university-affiliated hospitals. Forty-one percent of the surveyed units belong to hospitals with $<500$ beds. In 2007 , $35(80 \%)$ of the RHDCUs had an ICU within the RHDCU's hospital, and an ICU was less than $30 \mathrm{~km}$ away from 8 (18\%) of the RHDCUs, and more than $30 \mathrm{~km}$ from one of the RHDCUs.

\section{Levels of Care and Resources}

The number of RMUs, RIICU, and RICUs all increased from 1997 to 2007. The percentage growth was greatest for RMUs. RHDCUs working as independent units (ie, not located within a respiratory ward) decreased in favor of those located within a respiratory ward (Table 2).

The mean physician-to-patient ratio and nurse-to-patient ratio per daytime shift decreased from 1997 to 2007 in the RHDCUs overall, and in the RIICUs, but not in the RMUs and RICUs (Table 3). The proportion of dedicated physiotherapists decreased, but not significantly: 54\% in 1997 versus $48 \%$ in $2007(P=.62)$. Comparison of the change in "healthcarers" (described below) was not possible, due to the lack of data in the 1997 survey.

The availability of multi-variable monitors, intensive care ventilators, iron lung ventilators, and equipment to assess respiratory mechanics and pulmonary hemodynamics did not significantly change from 1997 to 2007 (Fig. 1). Ninety-six percent of the RHDCUs had NIV ventilators in 2007.

\section{Interventions, Diseases, and Outcomes}

According to the hospital discharge sheets, 5,289 patients were admitted in 2007 in the surveyed RHDCUs. Compared to 1997, only admissions for monitoring decreased, in contrast to the increase in admissions for active interventions (Table 4). 
Table 2. Levels of Care and Locations of Italian Respiratory High-Dependency Care Units in 1997 Versus 2007

\begin{tabular}{|c|c|c|c|c|c|}
\hline & \multicolumn{3}{|c|}{ RHDCU Type, no. (\%) } & \multicolumn{2}{|c|}{ Location, no. (\%) } \\
\hline & RMU & RIICU & RICU & $\begin{array}{c}\text { In a } \\
\text { Respiratory Ward }\end{array}$ & $\begin{array}{c}\text { Not in a } \\
\text { Respiratory Ward }\end{array}$ \\
\hline 1997 ( $n=26$ RHDCUs) & $2(8)^{*}$ & $20(77)$ & $4(15)$ & $17(65) \dagger$ & $9(35) \dagger$ \\
\hline 2007 ( $n=44$ RHDCUs) & $13(30)^{*}$ & $24(55)$ & $7(16) \ddagger$ & $36(82) \dagger$ & $8(18) \dagger$ \\
\hline \multicolumn{6}{|c|}{$\begin{array}{l}* P=.03 \text { for RMUs in } 1997 \text { vs RMUs in } 2007 . \\
\dagger P=.03 \text { for independent vs inside a respiratory ward in } 1997 \text { vs } 2007 . \\
\ddagger \text { Percentages do not sum to } 100 \text { because of rounding. } \\
\text { RHDCU = respiratory high-dependency care unit } \\
\text { RMU = respiratory monitoring unit } \\
\text { RIICU = respiratory intermediate intensive care unit } \\
\text { RICU = respiratory intensive care unit }\end{array}$} \\
\hline
\end{tabular}

Table 3. Physician and Nurse Availability in Italian Respiratory High-Dependency Care Units in 1977 Versus 2007

\begin{tabular}{|c|c|c|c|c|}
\hline & Year & No. & $\begin{array}{c}\text { Physician-to-Patient } \\
\text { Ratio } \\
\text { (mean } \pm \mathrm{SD})\end{array}$ & $\begin{array}{c}\text { Nurse-to-Patient } \\
\text { Ratio } \\
\text { (mean } \pm \mathrm{SD})\end{array}$ \\
\hline \multirow[t]{2}{*}{ RHDCU } & 1997 & 26 & $1: 4.5 \pm 1.9$ & $1: 3.2 \pm 1.1$ \\
\hline & 2007 & 44 & $1: 11.6 \pm 10.0^{*}$ & $1: 4.4 \pm 1.6 \dagger$ \\
\hline \multirow[t]{2}{*}{ RMU } & 1997 & 2 & $1: 5.0 \pm 1.4$ & $1: 5.5 \pm 0.7$ \\
\hline & 2007 & 13 & $1: 13.8 \pm 12.2$ & $1: 5.7 \pm 1.6$ \\
\hline \multirow[t]{2}{*}{ RIICU } & 1997 & 20 & $1: 4.6 \pm 2.0$ & $1: 3.1 \pm 0.8$ \\
\hline & 2007 & 24 & $1: 12.4 \pm 9.6 \ddagger$ & $1: 4.2 \pm 1.3 \S$ \\
\hline \multirow[t]{2}{*}{ RICU } & 1997 & 4 & $1: 4.0 \pm 2.1$ & $1: 2.5 \pm 0.6$ \\
\hline & 2007 & 7 & $1: 5.1 \pm 2.0$ & $1: 2.5 \pm 0.5$ \\
\hline \multicolumn{5}{|c|}{$\begin{array}{l}* P=.001 \text { for RHDCUs in } 1997 \text { vs RHDCUs in } 2007 . \\
\dagger P=.002 \text { for RHDCUs in } 1997 \text { vs RHDCUs in } 2007 . \\
¥ P=.001 \text { for RIICUs in } 1997 \text { vs RIICUs in } 2007 . \\
\S P=.002 \text { for RIICUs in } 1997 \text { vs RIICUs in } 2007 . \\
\text { RHDCU = respiratory high-dependency care unit } \\
\text { RMU = respiratory monitoring unit } \\
\text { RIICU = respiratory intermediate intensive care unit } \\
\text { RICU = respiratory intensive care unit }\end{array}$} \\
\hline
\end{tabular}

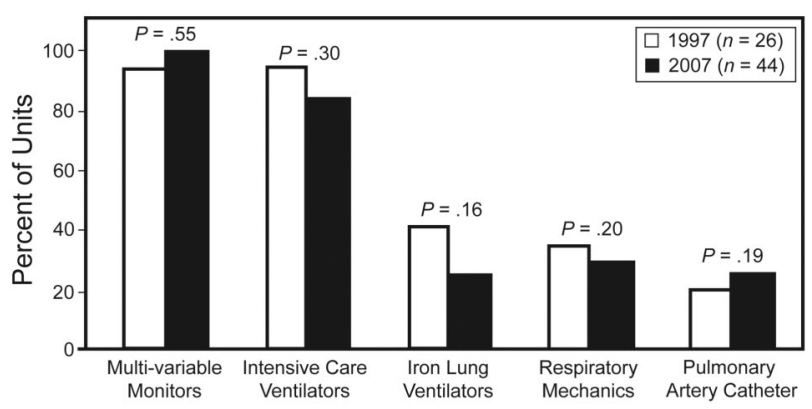

Fig. 1. Changes in equipment resources in Italian Respiratory HighDependency Care Units between 1997 and 2007.

Among the patients undergoing NIV, 90\% received positive-pressure NIV. Among the invasively ventilated patients, $80 \%$ had been tracheostomized in the ICU. End-oflife care was the main reason for RHDCU admission in $4 \%$ of the patients in 2007.
Table 4. Number of Patients and Interventions* in Italian Respiratory High-Dependency Care Units in 1997 Versus 2007

\begin{tabular}{|c|c|c|c|}
\hline & \multicolumn{2}{|c|}{ RHDCU } & \multirow[b]{2}{*}{$P$} \\
\hline & $\begin{array}{c}1997 \\
(n=26)\end{array}$ & $\begin{array}{c}2007 \\
(n=44)\end{array}$ & \\
\hline Patients, no. & 3,363 & 5,289 & \\
\hline Monitoring (\%) & 27 & 15 & $<.001$ \\
\hline Noninvasive ventilation (\%) & 53 & 56 & .002 \\
\hline Invasive ventilation (\%) & 20 & 29 & $<.001$ \\
\hline Weaning $(\%)$ & $8 \dagger$ & 19 & $<.001$ \\
\hline Decannulation (\%) & $4 \dagger$ & 10 & $<.001$ \\
\hline \multicolumn{4}{|c|}{$\begin{array}{l}\text { * The sum of all the interventions is greater than } 100 \% \text { because weaning and decannulation } \\
\text { were performed in patients who had required invasive ventilation. } \\
\dagger n=756 \text { patients. } \\
\text { RHDCU }=\text { respiratory high-dependency care unit }\end{array}$} \\
\hline
\end{tabular}

In $86 \%$ of the RHDCUs surveyed in 2007, NIV was also performed in other settings (mainly in an ICU or emergency department). A shared and integrated pathway for the hospital care of ARF was used in $61 \%$ of cases.

Concerning the causes of ARF, the number of patients with COPD decreased, the number with neuromyopathies and de novo hypoxemic ARF increased, and there was no significant change in obesity-hypoventilation syndrome, chest-wall deformities, or diffuse-interstitial lung disease (Fig. 2). Table 5 compares the "crude" patient outcomes in the surveyed Italian RHDCUs in 1997 and 2007.

\section{Care Levels of RHDCUs Surveyed in 2007}

While $100 \%$ of the RMUs and $88 \%$ of RIICUs were located inside a respiratory ward, the majority of RICUs $(57 \%)$ worked as independent entities. Only a small percentage of RIICUs (8\%) and RICUs (14\%) were within a multidisciplinary department. 


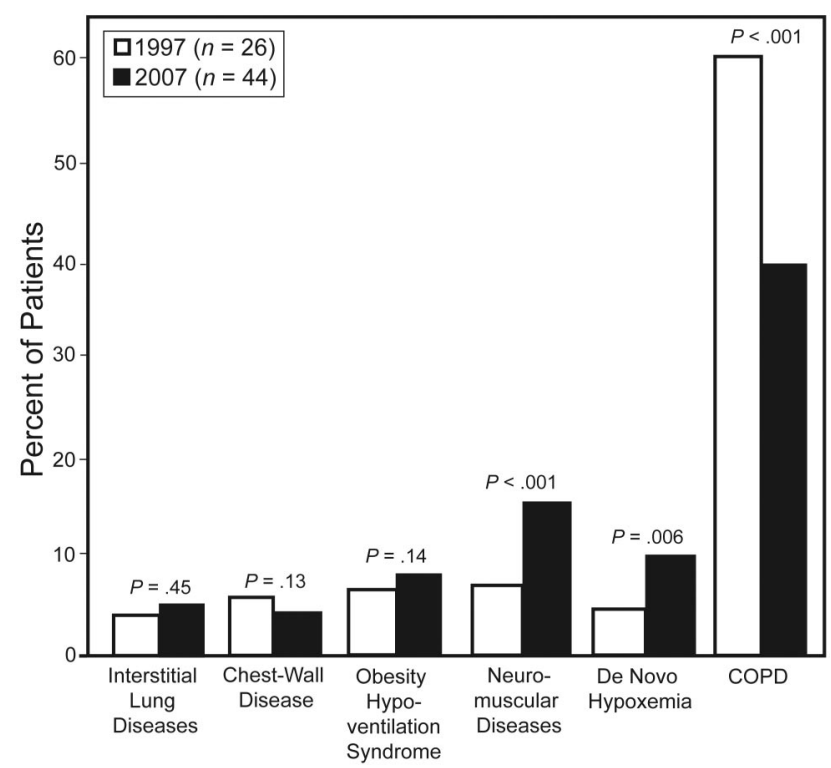

Fig. 2. Diseases in patients admitted to surveyed Italian Respiratory High-Dependency Care Units in 1997 and 2007.

The staffing (Table 6), types of interventions performed (Fig. 3), and "crude" patient outcomes (see Table 5) varied according to the care level in 2007.

\section{Discussion}

We report the time-course of Italian RHDCUs from the perspective of their role in the management of the increasing number of respiratory critical care patients in an era of overcrowded ICUs. ${ }^{1}$ This is the first systematic study of temporal trends in the number, structure, human and equipment resources, procedures, treated diseases, and outcomes in Italian RHDCUs. Our high survey response rate (90\%) is a point in favor of the applicability of our data. This second national survey found that between 1997 and 2007 there was a substantial increase in the number and expertise of Italian RHDCUs, as demonstrated by more active interventions (as opposed to only monitoring), and increased complexity of patient conditions in Italian RHDCUs, despite the fact that the most substantial growth was of low-level units.

\section{Number, Geographic Distribution, Institution}

The first 2 units dedicated to ARF treatment were set up at the end of the 1960s. Then it took about 3 decades to reach 26 RHDCUs, in $1997,{ }^{15,16}$ and another 10 years to get to the 44 in this survey. There has been a similar historical trend in other European countries..$^{917-20}$ The increasing popularity and effectiveness of NIV in ARF of various etiologies, ${ }^{10-12}$ and the possibility of treating COPD exacerbations $^{4}$ with NIV in the RHDCU with the same likelihood of success and with lower costs than in an ICU, have contributed to the growth of RHDCUs. ${ }^{9,15,16}$

According to the recent European survey, ${ }^{9}$ Italy was the country with the highest number of RHDCUs. This was largely due to the dissemination of related literature data, ${ }^{13,14}$ and a campaign to stimulate the official recognition of the role of RHDCUs. ${ }^{21}$ Unfortunately, even if the cost of managing ARF in chronic respiratory patients is lower in an RHDCU than in an ICU, ${ }^{4}$ there is still not adequate reimbursement for NIV. ${ }^{22}$

Similar to 1997 , the majority of the RHDCUs surveyed in 2007 belong to non-university-affiliated hospitals, whereas only a few were at university-affiliated hospitals. Thus may be due to the still minor "academic role" that pulmonologists have in intensive care medicine in Italy, as in other European countries. ${ }^{6}$ Moreover, a relevant-even if minor-number of RHDCUs were located in a rehabilitation centers, which, differently from those belonging to the hospitals, work as step-down units for ICUs, as they are mostly dedicated to the care of difficult to wean and tracheostomized patients. ${ }^{23}$

For more than one fifth of the surveyed RHDCUs, there was not an ICU located within the same institution; this is a critical point about RMUs, which are not able to manage severely ill patients needing invasive monitoring and/or ventilation.

\section{Levels of Care, Locations, and Resources}

The greatest growth in Italian RHDCUs was in RMUs located inside a respiratory ward. This Italian RHDCU model, with a flexible step-down and step-up integration within the same respiratory unit, is shared by other European countries. In France, 3 different RHDCU levels ( 2 that can provide invasive ventilation and NIV, and one that can provide only NIV) were reported to be working close with respiratory wards. ${ }^{20}$ Similarly, most of the German RHDCUs are located within respiratory medicine departments. ${ }^{19}$ In Spain in 2005, 14 of 16 RHDCUs surveyed were located inside a respiratory ward and provided NIV as the main activity. 18

The reduced nurse-to-patient and physician-to-patient ratio from 1997 to 2007 in all the RHDCUs reflected at least in part the increased number of less-staffed RMUs; in fact, the numbers of nurses and physicians did not change significantly in the RMUs and RICUs, whereas RIICUs had a decrease in physician and nurse resources.

The greater rate of expansion of RMUs, versus RIICUs and RICUs, may be the result of the optimization of Italy's restricted health resources. Despite the role played by physiotherapy in respiratory critical patients, ${ }^{24}$ the physiotherapist-to-patient ratio was low in all the RHDCU levels. Our finding parallels the results of a recent analysis of 5 Italian RHDCUs, which found a substantial staffing decrease over time. ${ }^{23}$ In this survey the "healthcarer" posi- 
Table 5. Crude Patient Outcomes in Italian Respiratory High-Dependency Care Units in 1997 Versus 2007

\begin{tabular}{|c|c|c|c|c|c|}
\hline & \multirow{2}{*}{$\begin{array}{l}1997 \\
\text { RHDCU } \\
(n=26)\end{array}$} & \multicolumn{4}{|c|}{2007} \\
\hline & & $\begin{array}{l}\text { RHDCU } \\
(n=44)\end{array}$ & $\begin{array}{c}\text { RMU* }^{*} \\
(n=13)\end{array}$ & $\begin{array}{c}\text { RIICU } \\
(n=24)\end{array}$ & $\begin{array}{c}\text { RICU } \\
(n=7)\end{array}$ \\
\hline Patients, no. & 756 & 5,289 & 1,328 & 3,031 & 930 \\
\hline Discharged home alive (\%) & 48 & 51 & 64 & 51 & 32 \\
\hline Transferred to respiratory ward $(\%)$ & 33 & 34 & 23 & 32 & 52 \\
\hline Transferred to ICU $(\%)$ & 6 & 5 & 6 & 5 & 3 \\
\hline Died in hospital $(\%)$ & 13 & 10 & 8 & 12 & 13 \\
\hline $\begin{array}{l}\text { * Percentages do not sum to } 100 \text { because of roundi } \\
\text { RHDCU = respiratory high-dependency care unit } \\
\text { RMU = respiratory monitoring unit } \\
\text { RIICU = respiratory intermediate intensive care un } \\
\text { RICU = respiratory intensive care unit }\end{array}$ & & & & & \\
\hline
\end{tabular}

Table 6. Human Resources in Italian Respiratory High-Dependency Care Units in 2007

\begin{tabular}{|c|c|c|c|}
\hline & $\begin{array}{c}\text { RMU } \\
(n=13)\end{array}$ & $\begin{array}{c}\text { RIICU } \\
(n=24)\end{array}$ & $\begin{array}{c}\text { RICU } \\
(n=7)\end{array}$ \\
\hline \multicolumn{4}{|l|}{ Nurses } \\
\hline Dedicated/shared* $(\%)$ & $31 / 69$ & $75 / 25$ & $71 / 29$ \\
\hline Nurse-to-patient ratio (mean $\pm \mathrm{SD}$ ) & $1: 5.7 \pm 1.6$ & $1: 4.2 \pm 1.3$ & $1: 2.5 \pm 0.5$ \\
\hline \multicolumn{4}{|l|}{ Physicians } \\
\hline Dedicated/shared* $(\%)$ & $23 / 77$ & $83 / 17$ & $100 / 0$ \\
\hline Physician-to-patient ratio (mean $\pm \mathrm{SD}$ ) & $1: 13.8 \pm 12.2$ & $1: 12.4 \pm 9.6$ & $1: 5.1 \pm 2.0$ \\
\hline \multicolumn{4}{|l|}{ Physiotherapists } \\
\hline Dedicated/shared* $(\%)$ & $54 / 47 \dagger$ & $38 / 64 \dagger$ & $71 / 30 \dagger$ \\
\hline Physiotherapist-to-patient ratio (mean $\pm \mathrm{SD}$ ) & $1: 17.2 \pm 9.2$ & $1: 13.9 \pm 11.8$ & $1: 16.7 \pm 12.6$ \\
\hline \multicolumn{4}{|l|}{ Healthcarers } \\
\hline Dedicated/shared $*(\%)$ & $17 / 83$ & $29 / 71$ & $43 / 43 \ddagger$ \\
\hline Healthcarers-to-patient ratio (mean $\pm \mathrm{SD}$ ) & $1: 14.2 \pm 9.4$ & $1: 19.9 \pm 14.9$ & $1: 14.2 \pm 9.4$ \\
\hline $\begin{array}{l}\text { * Shared with a respiratory ward or department. } \\
\dagger \text { Percentages do not sum to } 100 \text { because of rounding. } \\
\text { ¥Absent in } 14 \% \text { of the RICUs. } \\
\text { RHDCU = Respiratory High-Dependency Care Unit } \\
\text { RICU = Respiratory Intensive Care Unit } \\
\text { RIICU = Respiratory Intermediate Intensive Care Unit } \\
\text { RMU = Respiratory Monitoring Unit }\end{array}$ & & & \\
\hline
\end{tabular}

tion was considered for the first time in an analysis of RHDCU human resources. Healthcarer is a new professional position; healthcarers support nurses in the care of patients' primary needs (eg, bed rearrangement, patient positioning and cleaning, food distribution). The healthcarer has no direct involvement in the medical management of the patient, but the healthcarer's support in the management of RHDCU facilities (eg, collection, washing, and replacement of interfaces, tracheal cannula, circuits, ventilators) should not be undervalued.

Equipment for monitoring and mechanical ventilation did not significantly change between 1997 and 2007. Almost all the RHDCUs were equipped with one multi-variable monitor per bed, which could continuously collect noninvasive physiological monitoring data. Invasive respi- ratory mechanics and pulmonary hemodynamics monitoring is available in only a few of the RHDCUs, as we would expect because the number of invasive devices is usually lower than that routinely applied in an ICU, which has the advantage of reduced risk of nosocomial infection.,25 Moreover, noninvasive physiological data at baseline and after 2 hours of NIV can accurately predict the likelihood of NIV failure in COPD exacerbation. ${ }^{26}$ Almost all the RHDCUs had NIV ventilators, which, in contrast to older-generation ICU ventilators, can adequately compensate for air leaks. ${ }^{27}$

\section{Interventions, Diseases, and Outcomes}

Compared to the data reported for each level of care in the European RHDCU survey, ${ }^{9}$ the Italian RHDCUs ad- 


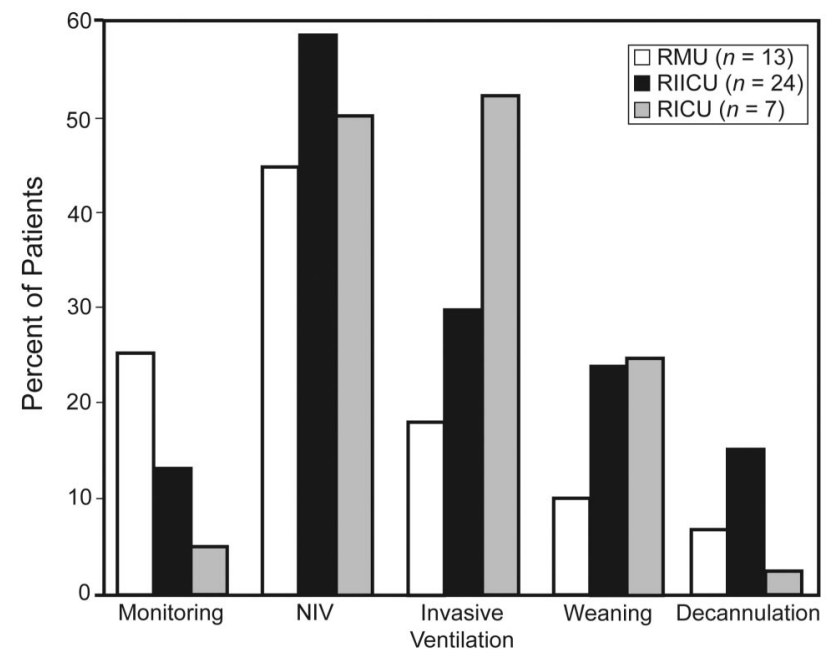

Fig. 3. Distribution of interventions in the surveyed Italian Respiratory High-Dependency Care Units in 2007. $P<.001$ for all comparisons except noninvasive ventilation (NIV) in respiratory monitoring units (RMUs) vs in respiratory intensive care units (RICUs) $(P=.01)$, and weaning in respiratory intermediate intensive care unit (RIICUs) vs in RICUs $(P=.66)$.

mitted a lower percentage of patients for monitoring only. The cost/benefit ratio for active treatments (eg, mechanical ventilation, weaning, and decannulation) for a patient with a decompensation of a chronic respiratory disease may be favorable in an RHDCU, compared to an ICU. ${ }^{4}$ This is true for Italian units not only for patients who are successfully treated with NIV, ${ }^{4}$ but also for tracheostomized patients. ${ }^{28}$ The advantages of a new model for long-term weaning, based on the integrated activity of one Italian RHDCU and one weaning center run by the same pulmonology team, were recently described. ${ }^{29}$

We speculate that the changes in the pattern of diseases admitted to RHDCUs may be the result of 3 factors:

- The increasing success and cost savings of NIV to treat COPD exacerbation in other hospital settings (eg, general ward or emergency department), ${ }^{17,30}$ as observed also in this survey: $86 \%$ of the respondent RHDCUs reported the use of NIV in other environments.

- The extensive literature and data supporting the use of NIV in patients with neuromyopathies..$^{23,31}$

- The increased use of NIV as a cautious attempt to treat de novo ARF before resorting to intubation and a highlevel care setting. ${ }^{32}$

The increased complexity of both the interventions performed and the patients treated in Italian RHDCUs reflects increasing expertise in dealing with critically ill patients. This is in agreement with previously published data that showed that increasing experience with NIV may progres- sively allow more severely ill patients to be treated without changing the NIV success rate. ${ }^{33}$

The crude mortality rates found in the 2 Italian RHDCU surveys are similar to those reported for COPD exacerbations managed with NIV (10-25\%). ${ }^{34-36}$ However, those data were obtained from hospital discharge sheets, which lack information about important confounders such as disease severity, comorbidities, and interventions.

\section{Limitations}

First, between 1997 and 2007 there were important changes in the clinical management of ARF in the RHDCU setting (eg, new patient/ventilator interfaces and NIV ventilators), which may limit the comparability of the data and may have favored the 2007 survey.

Second, the lack of data on the financial impact of RHDCUs on ICU and overall hospital resources (eg, ICU bed occupancy, hospital stay, admission recurrence) does not allow us to draw economic conclusions.

Finally, unfortunately, the 1997 survey did not collect some important details on the study population (eg, severity of illness score, arterial blood gas values, and comorbidities), so we cannot exclude that there may have been important changes in such factors between 1997 and 2007 that might have influenced the site where RHDCU care was provided and the complexity of interventions performed.

\section{Conclusions}

Between 1997 and 2007 there was substantial growth in the number and expertise of Italian RHDCUs. Given the shift toward a less expensive pattern and a greater complexity of interventions and diagnoses, RHDCUs play a crucial role in the management of respiratory critical care patients. Cost/ benefit financial studies of RHDCUs are warranted.

\section{REFERENCES}

1. Global Initiative for Chronic Obstructive Lung Disease. Global strategy for diagnosis, management and prevention of COPD. Updated 2008. http://www.goldcopd.com. Accessed June 10, 2009.

2. Corrado A, Gorini M. The evolution and the current status of respiratory intensive care in Europe. Clinical Pulmonary Medicine 2002; 9(6):342-346.

3. Price LC, Lowe D, Hosker HS, Anstey K, Pearson MG, Roberts CM. British Thoracic Society and the Royal College of Physicians Clinical Effectiveness Evaluation Unit (CEEu). UK National COPD Audit 2003: impact of hospital resources and organisation of care on patient outcome following admission for acute COPD exacerbation. Thorax 2006;61(10):837-842.

4. Bertolini G, Confalonieri M, Rossi C, Rossi G, Simini B, Gorini M, Corrado A; GiViTI (Gruppo italiano per la Valutazione degli interventi in Terapia Intensiva); AIPO (Associazione Italiana Pneumologi Ospedalieri). Costs of the COPD. Differences between intensive care 


\section{Italian Respiratory High-Dependency Care Units: The Second National Survey}

unit and respiratory intermediate care unit. Respir Med 2005;99(7): 894-900.

5. Nava S, Confalonieri M, Rampulla C. Intermediate respiratory intensive care units in Europe: a European perspective. Thorax 1998; 53(9):798-802.

6. Evans T, Elliott MW, Ranieri M, Seeger W, Similowski T, Torres A, Roussos C. Pulmonary medicine and (adult) critical care medicine in Europe. Eur Respir J 2002;19(6):1202-1206.

7. Petty TL, Lakshminarayan S, Sahn SA, Zwillich CW, Nett LM. Intensive respiratory care unit. Review of ten years' experience. JAMA 1975;233(1):34-37.

8. Bone RC, Balk RA. Noninvasive respiratory care unit. A cost effective solution for the future. Chest 1988;93(2):390-394.

9. Corrado A, Roussos C, Ambrosino N, Confalonieri M, Cuvelier A, Elliott M, et al. European Respiratory Society Task Force on epidemiology of respiratory intermediate care in Europe. Respiratory intermediate care units: a European survey. Eur Respir J 2002;20(5): $1343-1350$

10. Nava $\mathrm{S}$, Hill N. Non-invasive ventilation in acute respiratory failure. Lancet 2009;374(9865):250-259.

11. Ambrosino N, Vagheggini G. Noninvasive positive pressure ventilation in the acute care setting: where are we? Eur Respir J 2008; 31(4):874-886.

12. Corrado A, Gorini M, Melej R, Baglioni S, Mollica C, Villella G, et al. Iron lung versus mask ventilation in acute exacerbation of COPD: a randomised crossover study. Intensive Care Med 2009;35(4):648-655.

13. Corrado A, Ambrosino N, Rossi A, Donner CF; AIPO (Associazione Italiana Pneumologi Ospedalieri) Study Group of Rehabilitation and Respiratory Intensive Care. Unità di Terapia Intensiva Respiratoria Rass Pat App Respir 1994;9:115-123.

14. Corrado A, Ambrosino N, Cavalli A, Gorini M, Navalesi P, Confalonieri $\mathrm{M}$, et al. Unità di terapia intensiva respiratoria: update. Rass Patol App Respir 2004;19:18-34. Article in Italian.

15. Confalonieri M, Mollica C, Nava S, Corrado A. Censimento delle unità di terapia intensiva respiratoria in Italia. Rass Pat App Respir 1998;13:186-192. Article in Italian.

16. Confalonieri M, Gorini M, Ambrosino N, Mollica C, Corrado A; Scientific Group on Respiratory Intensive Care of the Italian Association of Hospital Pneumologists. Respiratory intensive care units in Italy: a national census and prospective cohort study. Thorax 2001;56(5):373-378.

17. Plant PK, Owen JL, Elliott MW. Early use of non-invasive ventilation for acute exacerbations of chronic obstructive pulmonary disease on general respiratory wards: a multicentre randomised controlled trial. Lancet 2000;355(9219):1931-1935.

18. Torres A, Ferrer M, Blanquer JB, Calle M, Casolivé V, Echave JM, Masa DM; Grupo de Trabajo de Cuidados Respiratorios Intermedios de la Sociedad Española de Neumología y Cirugía Torácica (SEPAR). Intermediate respiratory intensive care units: definitions and characteristics. Arch Bronconeumol 2005;41(9):505-512.

19. Schönhofer B. Respiratory high-dependency units in Germany. Monaldi Arch Chest Dis 1999;54(5):448-451.

20. Muir JF, Mayaud C, Derenne JP. Respiratory high dependency care units (RHDCU) in France. Monaldi Arch Chest Dis 1999;54(5):452455 .
21. Italian Health Ministry. Respiratory Diseases. National Health Programme 2006-2008. http://www.ministerosalute.it/resources/ static/primopiano/316/PSN_2006_08_28_marzo.pdf. Accessed June 9, 2011.

22. Criner GJ, Kreimer DT, Tomaselli M, Pierson W, Evans D. Financial implications of non invasive positive pressure ventilation (NPPV). Chest 1995;108(2):475-481.

23. Polverino E, Nava S, Ferrer M, Ceriana P, Clini E, Spada E, et al. Patient's characterisation, hospital course and clinical outcomes in five Italian respiratory intensive care units. Intensive Care Med 2010; 36(1):137-142.

24. Clini E, Ambrosino N. Early physiotherapy in the respiratory intensive care unit. Respir Med 2005;99(9):1096-1104.

25. Scala R, Nava S, Conti G, Antonelli M, Naldi M, Archinucci I, et al. Noninvasive versus conventional ventilation to treat hypercapnic encephalopathy in chronic obstructive pulmonary disease. Intensive Care Med 2007;33(12):2101-2108.

26. Confalonieri M, Garuti G, Cattaruzza MS, Osborn JF, Antonelli M, Conti G, et al. Italian noninvasive positive pressure ventilation (NPPV) study group. A chart of failure risk for noninvasive ventilation in patients with COPD exacerbation. Eur Respir J 2005;25(2):348-355.

27. Scala $R$, Naldi M. Ventilators for noninvasive ventilation to treat acute respiratory failure. Respir Care 2008;53(8):1054-1080.

28. Marchese S, Corrado A, Scala R, Corrao S, Ambrosino N. Tracheostomy in patients with long-term mechanical ventilation: A survey. Respir Med 2010;104(5):749-753

29. Carpenè N, Vagheggini G, Panait E, Gabbrielli L, Ambrosino N. A proposal of a new model for long-term weaning: Respiratory Intensive Care Unit and Weaning Center. Respir Med 2010;104(10):1505-1511.

30. Bolton R, Bleetman A. Non-invasive ventilation and continuous positive pressure ventilation in emergency departments: where are we now? Emerg Med J 2008;25(4):190-194.

31. Ambrosino N, Carpenè N, M. Gherardi M. Chronic respiratory care in neuromuscular diseases for adults. Eur Respir J 2009; 34(2):444-451.

32. Demoule A, Girou E, Richard JC, Taillé S, Brochard L. Increased use of noninvasive ventilation in French intensive care units. Intensive Care Med 2006;32(11):1747-1755.

33. Carlucci A, Delmastro M, Rubini F, Fracchia C, Nava S. Changes in the practice of non-invasive ventilation in treating COPD patients over 8 years. Intensive Care Med 2003;29(3):419-425.

34. Connors AF Jr, Dawson NV, Thomas C, Harrell FE Jr, Desbiens N, Fulkerson WJ, et al. Outcomes following acute exacerbation of severe chronic obstructive lung disease. The SUPPORT investigators (Study to Understand Prognoses and Preferences for Outcomes and Risks of Treatments). Am J Respir Crit Care Med 1996;154(4 Pt 1):959-967.

35. Nevins ML, Epstein SK. Predictors of outcome for patients with COPD requiring invasive mechanical ventilation. Chest 2001; 119: 1840-1849.

36. Scala R, Bartolucci S, Naldi M, Rossi M, Elliott MW. Co-morbidity and acute decompensations of COPD requiring non-invasive positive-pressure ventilation. Intensive Care Med 2004;30(9): $1747-1754$

This article is approved for Continuing Respiratory Care Educatior credit. For information and to obtain your CRCE

(free to AARC members) visit www.RCJournal.com

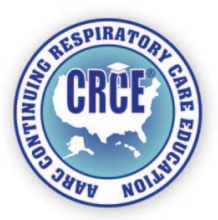

